\title{
Designing a PID controller for slab temperature control system
}

\author{
Kien Ngoc $\mathrm{Vu}{ }^{1,}{ }^{*}$, Tich Luong Ward ${ }^{2}$, Nga Thi Thanh Tran ${ }^{1}$ and Tich Luong Ward ${ }^{2}$ \\ ${ }^{1}$ Electrical Faculty, Thai Nguyen University of Technology, 666, 3/2 Street, Vietnam. \\ ${ }^{2}$ Thai Nguyen City, Vietnam.
}

Global Journal of Engineering and Technology Advances, 2021, 08(02), 001-007

Publication history: Received on 19 May 2021; revised on 27 July 2021; accepted on 29 July 2021

Article DOI: https://doi.org/10.30574/gjeta.2021.8.2.0108

\begin{abstract}
The problem of heating slab is a very important and highly applicable problem in the material processing industry. This paper presents a method to design a PID controller according to the characteristic polynomial method to control the temperature for slab based on the transfer function model. The parameters of the PID controller are determined based on the parameters of the slab model, the heating furnace model, the converter model. The simulation results show that: the PID controller is capable of controlling the temperature of the slab to the desired temperature without overadjusting.
\end{abstract}

Keywords: Slab; Transfer function model; PID controller; Heating furnace

\section{Introduction}

In many technological processes, heating materials is an important step. Heating only changes the properties of materials (mainly metal materials) by changing the internal structure without changing the shape and size of materials. Heating requires a tight and controlled process of the time and rate of heat exchange in the material. The heating of materials can be the final step to produce products, for example, firing bricks, ceramics, heat treatment of machine parts, sheet blanks, fiber optic cable fabrication, optical glass annealing, fabrication, ferromagnetic materials, annealing ferromagnetic materials, etc. but it can also be a process for further processing, i.e. heating of semi-finished products such as metal heating to serve hot rolling mills, machines hammer or forge. During the firing process, the technologyspecific parameters are the slab temperature and the temperature distribution in the slab. The necessary requirement in the heating problem is to control the temperature of the heating furnace according to the temperature requirements of the slab to ensure the technological requirements of the slab. According to control theory, in order to control the temperature of the slab - the object to be controlled according to the technological requirements, it is necessary to determine (measure) the temperature of the slab. There are two ways to determine the temperature of the slab:

- Option 1: Using a temperature sensor to directly measure the temperature in the slab

- Option 2: Indirectly measuring the temperature in the slab through measuring the furnace temperature.

Option 1 gives accurate results in measuring the temperature in the slab, but it is necessary to install temperature sensors in many places on the slab to determine the heat distribution in the slab. In practice, it is very difficult to mount multiple temperature sensors in the slab. With option 2, using the heat transfer model, the heat transfer equation in the workpiece, the temperature of the slab can be determined based on the furnace temperature. Thus, we only need one sensor temperature to measure the temperature of the furnace, so option 2 has high applicability in practice.

\footnotetext{
* Corresponding author: Kien Ngoc Vu; E-mail: kienvn@tnut.edu.vn

Thai Nguyen University of Technology, 666, 3/2 Street. 
The heat transfer equation in the slab is a partial differential equation [1]. Calculating the thermal field in the slab is to solve the above equation with specific conditions - or to build a mathematical model of the heat transfer process in the slab. There are two methods to build the model: numerical method [1, 2, 3] and transfer function model method [4], [4, $5,6]$. Numerical methods such as the dissociation of variables [1]; model method [2]; The finite element method [3] often has high complexity, so it is not suitable for the design of real control systems. The method of modeling slab as a transfer function $[3,4,5,6]$ is very suitable for the design of the controller. Therefore, in this paper, we use the transfer function slab model to design the PID controller. The layout of the next sections of the paper is as follows. Part 2 introduces the transfer function model of the slab. The design method of the PID controller for the slab is presented in part 3. Part 4 is the simulation and evaluation results. Conclusions are presented in section 5.

\section{Material and methods}

\subsection{Transfer function model of slab}

Consider the model of one-side heating furnace as follows

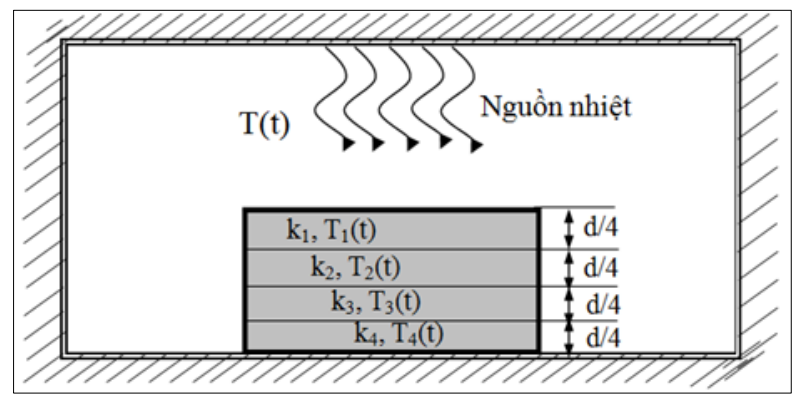

Figure 1 Heat transfer model of furnace

In the above model, the heat source for the slab $\mathrm{T}(\mathrm{t})$ comes from one side of the furnace. In order to make the calculation of the transfer function model of the furnace convenient, we have the following assumptions: The volume of the furnace chamber is small, considering the temperature in the furnace is the same; Neglect the heat transfer through the tip and edge of the slab.

The basic parameters of the slab are as follows

Thermal conductivity k: W/m.K; Heat transfer coefficient h: W/m²; Length l (m); width w (m); thickness d (m); specific weight $\rho: \mathrm{Kg} / \mathrm{m}^{3}$; specific heat c: J/kg.K; Contact surface area of the slab is $\mathrm{S}=\mathrm{l}^{*} \mathrm{~d}\left(\mathrm{~m}^{2}\right)$.

According to Figure 1, we divide the slab into $n$ layers. The process of transferring heat from the furnace heat to the first layer of the slab is mainly through radiant heat transfer. With this outer layer: The input of the model is the temperature in the furnace space, the output of the model is the temperature of the outer layer. Heat transfer between the layers of the slab is carried out by heat conduction. For inner layers of the slab: The input of the model is the temperature of the front layer, the output of the model is the temperature of the layer under consideration. With the way of determining the input and output of the above, in $[3,4,5,6]$, the transfer function model of the layers in the slab was built as follows:

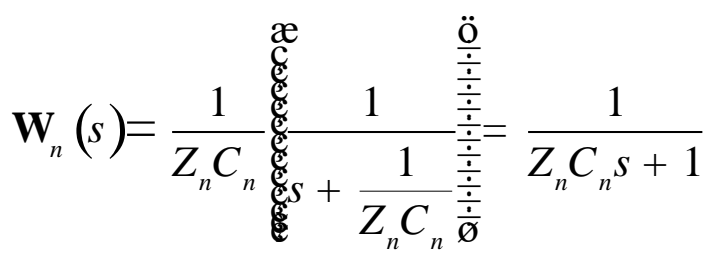

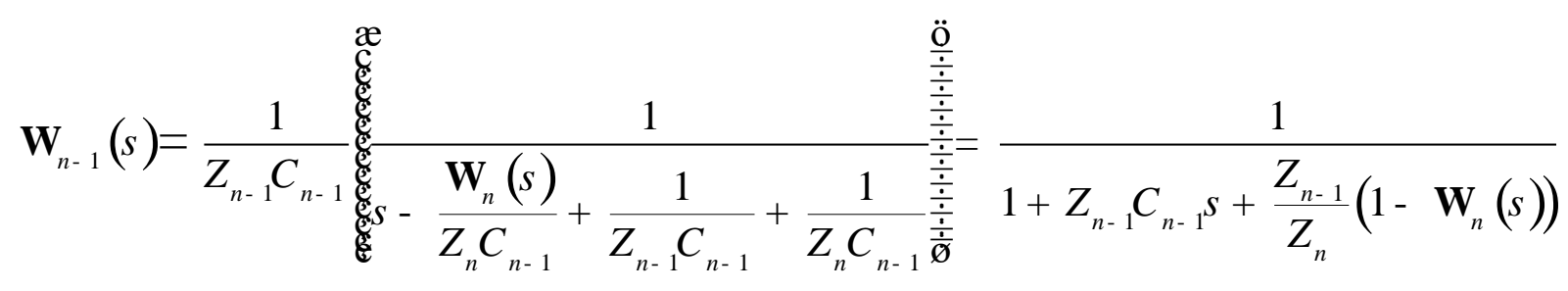




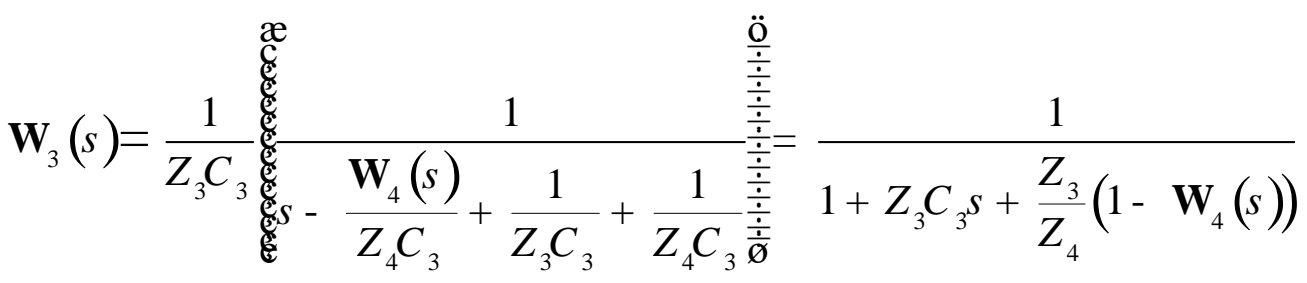

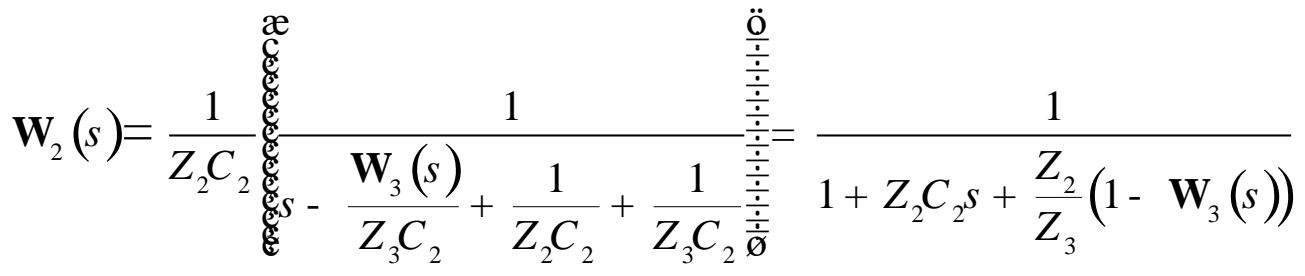

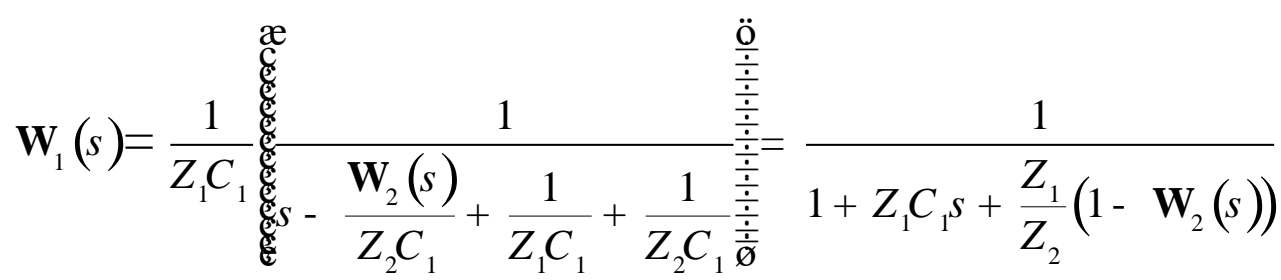

Which:

$$
Z_{1}=\frac{1}{S h}, Z_{2}=\frac{d / n}{S k_{1}}, Z_{3}=\frac{d / n}{S k_{2}} ; \ldots, Z_{n}=\frac{d / n}{S k_{n-1}}
$$

$C_{1}=m_{1} c, C_{2}=m_{2} c, \ldots, C_{n}=m_{n} c$

$m_{1}, m_{2}, . . m_{n}$ is the mass of the layer $1,2, . ., \mathrm{n}$

Consider a case of slab with the following parameters:

Thermal conductivity: $\mathrm{k}=55.8 \mathrm{w} / \mathrm{m} . \mathrm{K}$ (consider the thermal conductivity of the slab to be constant); Heat transfer coefficient $\mathrm{h}=335 \mathrm{w} / \mathrm{m}^{2}$; Length $\mathrm{l}=40 \mathrm{~cm}=0.4 \mathrm{~m}$; width $\mathrm{w}=25 \mathrm{~cm}=0.25 \mathrm{~m}$; thickness $\mathrm{d}=5 \mathrm{~cm}=0.05 \mathrm{~m}$; specific weight $\rho=7800 \mathrm{Kg} / \mathrm{m}^{3}$; specific heat $\mathrm{c}=460 \mathrm{~J} / \mathrm{kg} . \mathrm{K}$; Contact surface area of the slab is $\mathrm{S}=l^{*} \mathrm{w}=0.4^{*} 0.25=0.1 \mathrm{~m}^{2}$

Choosing $n=3$, we have the transfer function model of the layers as follows

Then the thickness of each layer is $\mathrm{d} / 3=0.05 / 3=0.0167 \mathrm{~m}$

The volume of each layer is $\mathrm{V}_{1}=\mathrm{V}_{2}=\mathrm{V}_{3}=0.4^{*} 0.25^{*} 0.0167=0.00167 \mathrm{~m}^{3}$.

The mass of each layer of slab: $m_{1}=m_{2}=m_{3}=V_{1}{ }^{*} \rho=0.00167^{*} 7800=13 \mathrm{~kg}$

$\mathrm{C}_{1}=\mathrm{C}_{2}=\mathrm{C}_{3}=\mathrm{m}_{1}{ }^{*} \mathrm{c}=13 * 460=5980$

$$
Z_{1}=\frac{1}{S h}=\frac{1}{0.1 * 335}=0.0299 ; Z_{2}=Z_{3}=\frac{d / 3}{k S}=\frac{0.0167}{55.8 * 0.1}=0.00299
$$

The transfer function of each layer of the slab is as follows

$$
\begin{aligned}
& \mathbf{W}_{3}(s)=\frac{1}{Z_{3} C_{3} s+1}=\frac{1}{17.86 s+1} \\
& \mathbf{W}_{2}(s)=\frac{1}{1+Z_{2} C_{2} s+\frac{Z_{2}}{Z_{3}}\left(1-\mathbf{W}_{3}(s)\right)}=\frac{17.86 s+1}{319 s^{2}+53.58 s+1} \\
& \mathbf{W}_{1}(s)=\frac{1}{1+Z_{1} C_{1} s+\frac{Z_{1}}{Z_{2}}\left(1-\mathbf{W}_{2}(\mathrm{~s})\right)}=\frac{319 s^{2}+53.58 s+1}{56950 s^{3}+13062 s^{2}+589.1 s+1}
\end{aligned}
$$




\subsection{PID controller design}

To control the temperature of the slab, we use the control system structure as follows:

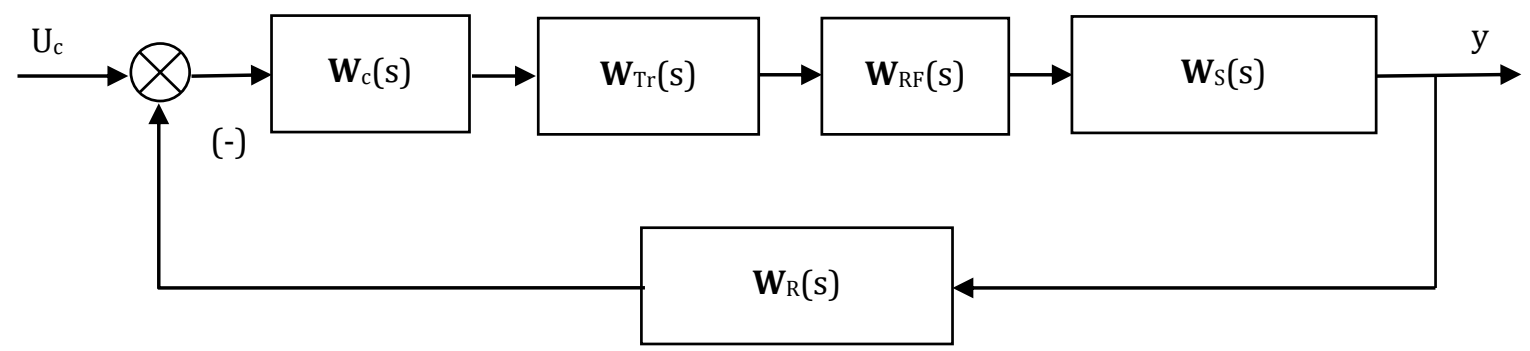

Figure 2 Structure diagram of slab temperature control system

The Tiristor converter has the following transfer function:

$\mathbf{W}_{T r}(s)=\frac{22}{0.0033+1}[4,5,6]$

Transfer function of the resistance furnace:

$\mathbf{W}_{R F}(s)=\frac{5 \cdot e^{-30 s}}{500 s+1}[4,5,6]$

The scale converter is described by the transfer function: $\mathbf{W}_{R}(s)=0.01[4,5,6]$

In order to control the temperature of the slab, we choose to control the temperature for the second layer of the slab. Then the slab model is determined by the following transfer function:

$$
\mathbf{W}_{S}(s)=\mathbf{W}_{2}(s) \cdot \mathbf{W}_{1}(s)=\frac{17.86 s+1}{319 s^{2}+53.58 s+1} \cdot \frac{319 s^{2}+53.58 s+1}{56950 s^{3}+13062 s^{2}+589.1 s+1}
$$

The transfer function of the control object has the following form:

$$
\begin{aligned}
& \mathbf{W}_{o}(s)=\mathbf{W}_{T r}(s) * \mathbf{W}_{R F}(s) * \mathbf{W}_{S}(s) \\
& =\frac{22}{0.0033 s+1} * \frac{5}{500 s+1} * \frac{1}{30 s+1} * \frac{17.86 s+1}{319 s^{2}+53.58 s+1} * \frac{319 s^{2}+53.58 s+1}{56950 s^{3}+13062 s^{2}+589.1 s+1}
\end{aligned}
$$

Simplifying the transfer function of the control object, we get the following result

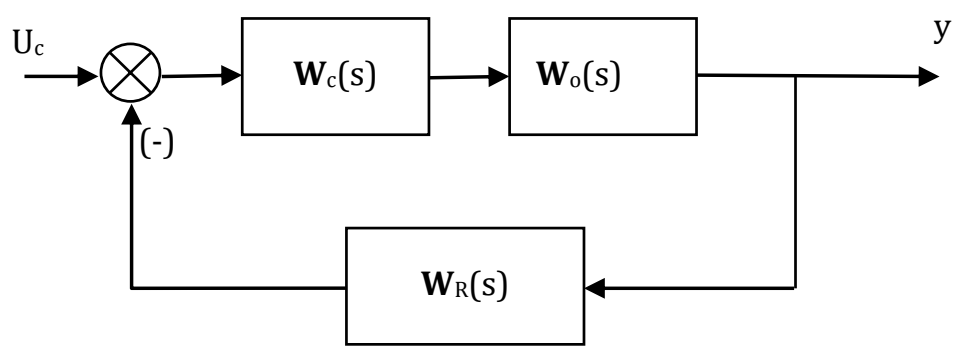

Figure 3 Structure diagram of temperature control system of the second layer of slab

$$
\begin{aligned}
& \mathbf{W}_{o}(s)=\frac{110}{(5.95 s+1) *(556 s+1) *(500 s+1) *(0.0033 s+1)} * \frac{1}{30 s+1} \\
& \hat{\mathrm{U}} \mathbf{W}_{o}(s)=\frac{110}{(556 s+1) *(500 s+1) *(30.59 s+1)}
\end{aligned}
$$

Consider the structure of the PID controller as follows: 


$$
\mathbf{W}_{c}(s)=K_{p}+K_{d} s+K_{i} \frac{1}{s}
$$

To determine the parameters of the PID controller, we follow the following steps:

Step 1: Find the closed-system transfer function

$$
\begin{aligned}
& \mathbf{W}_{k}(s)=\frac{\mathbf{W}_{c}(\mathrm{~s}) \cdot \mathbf{W}_{o}(\mathrm{~s})}{1+\mathbf{W}_{c}(\mathrm{~s}) \cdot \mathbf{W}_{o}(\mathrm{~s}) \cdot \mathbf{W}_{R}(s)} \\
& \mathrm{P} \quad \mathbf{W}_{k}(s)=\frac{110 K_{d} s^{2}+110 K_{p} s+110 K_{i}}{8504020 s^{4}+310303,84 s^{3}+\left(1086.59+1,1 K_{d}\right) s^{2}+\left(1+1,1 K_{p}\right) s+1,1 K_{i}}
\end{aligned}
$$

According to the characteristic polynomial method, because the numerator of the closed system has quadratic form, we need to bring the closed system to normal form as follows:

$$
\mathbf{W}(s)=\frac{a_{2}^{\prime} s^{2}+a_{1}^{\prime} s+a_{0}^{\prime}}{a_{4} s^{4}+a_{3} s^{3}+a_{2} s^{2}+a_{1} s+a_{0}}
$$

Step 2: Choose the coefficient $\alpha>1.6$, through many selections, the author chooses $\alpha=2.8$

From the above system of equations, we can determine the coefficients of the controller as follows:

$$
\begin{aligned}
& K_{p}=6,2 \\
& K_{i}=0,0052 \\
& K_{d}=1,86.10^{3}
\end{aligned}
$$

\section{Results and discussion}

Modeling of slabs in Matlab - Simulink is as follows

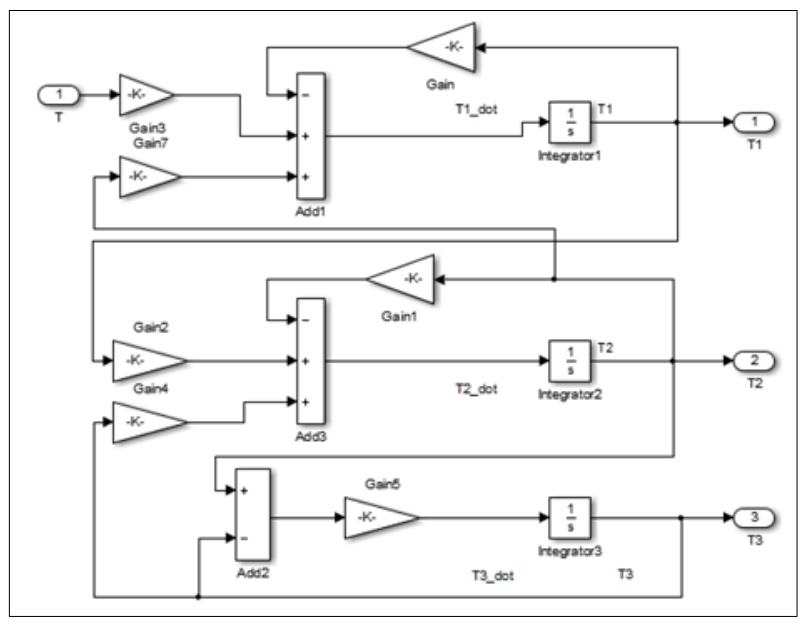

Figure 4 Model of 3-layer slab in Matlab - Simulink

Comment: The PID controller has controlled the temperature of the $2^{\text {nd }}$-layer of the slab to reach the set temperature (in the region $\pm 5 \%$ of the set value) with 445 s transient time, no over-adjustment. The maximum furnace temperature is $2131^{\circ} \mathrm{C}$. After $1000 \mathrm{~s}$, the temperature of all 3 layers of the slab are coincide. 


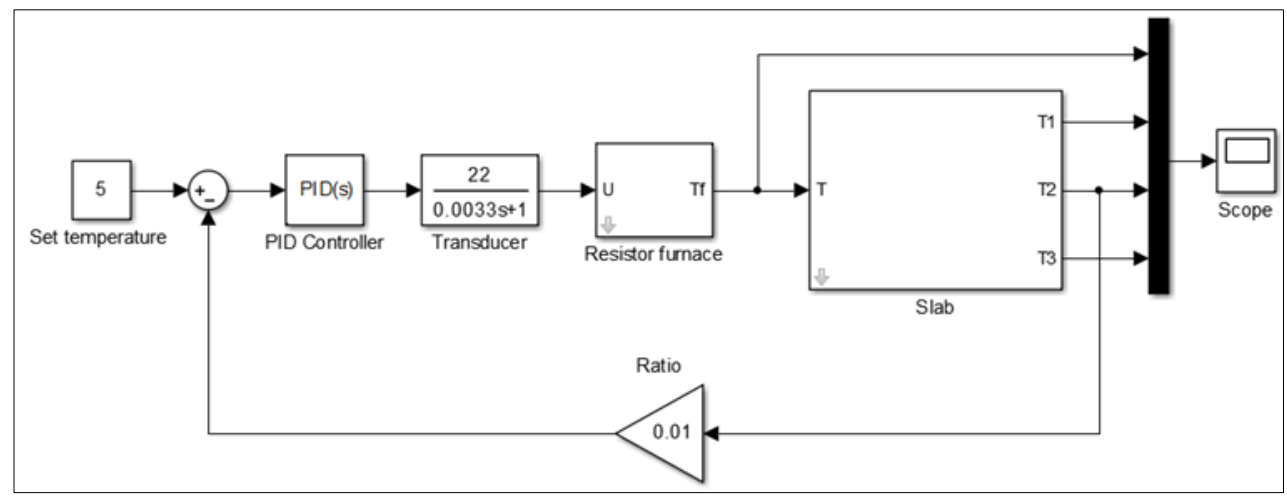

Figure 5 Simulation diagram of 3-layer slab temperature control system

With this control system, we perform temperature control of the $2^{\text {nd }}$ layer of the slab. The simulation results are as follows

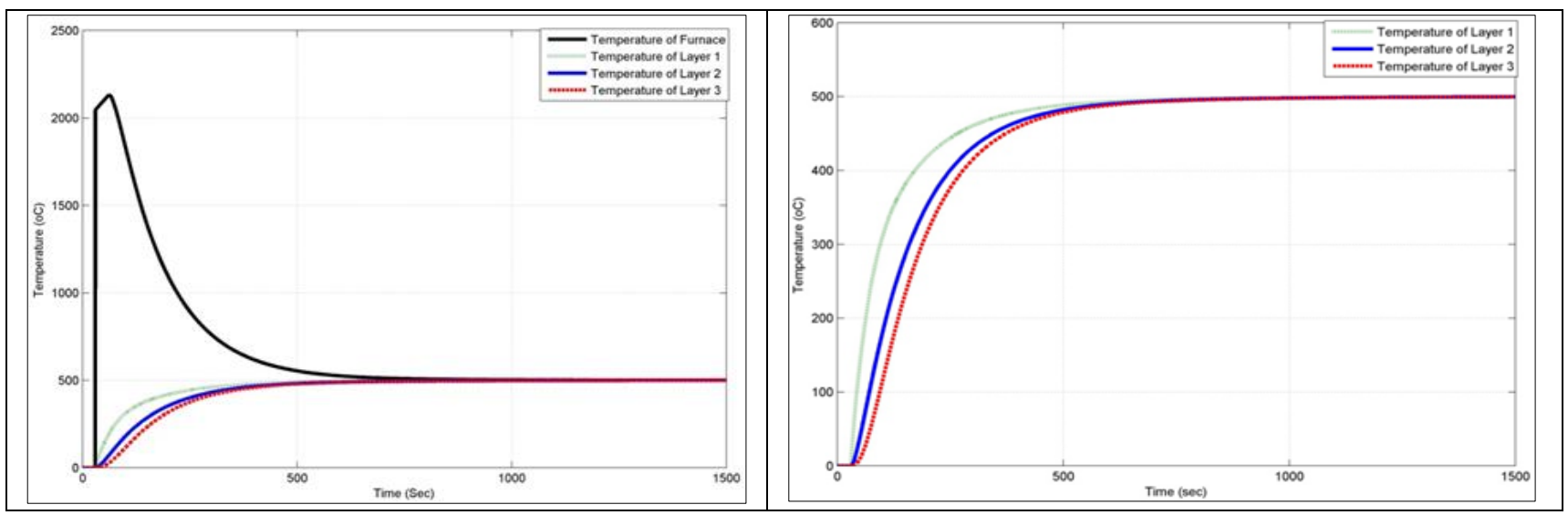

Figure 6 Simulation results of 3-layer slab temperature control system

To improve the quality of the control system, we add a filter behind the set signal. The structure diagram of the control system will have the following form:

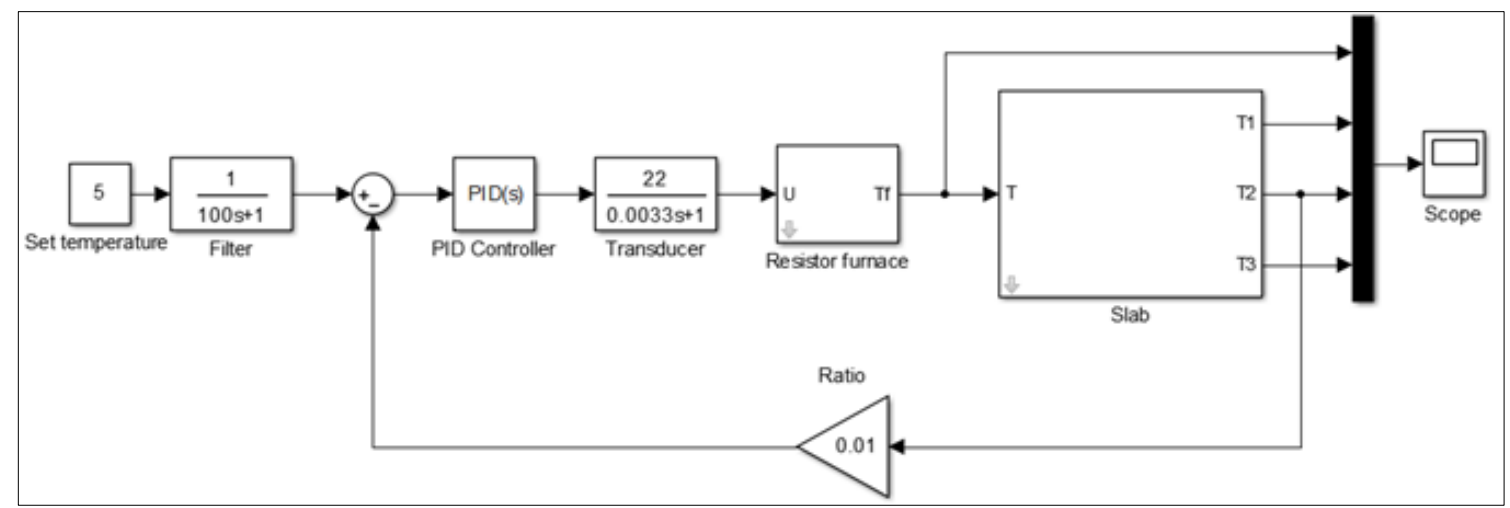

Figure 7 Simulation diagram of the 3-layer slab temperature control system when using filter

Remark: When adding a filter behind the set signal, the PID controller has controlled the temperature of the $2^{\text {nd-layer of }}$ the slab to reach the set temperature (within $\pm 5 \%$ of the set value) with $608 \mathrm{~s}$ transient time, no over-adjustment. The maximum furnace temperature is $1257^{\circ} \mathrm{C}$. After $1000 \mathrm{~s}$, the temperatures of all 3 layers of the slab are coincide.Thus, when adding a filter to the temperature control system of the slab, although the transition time increased (from $445 \mathrm{~s}$ to $608 \mathrm{~s}$ ), the maximum temperature of the furnace decreased (from $2131{ }^{\circ} \mathrm{C}$ to $125{ }^{\circ} \mathrm{C}$ ), reducing the maximum temperature of the furnace will help save heating energy for the furnace. 

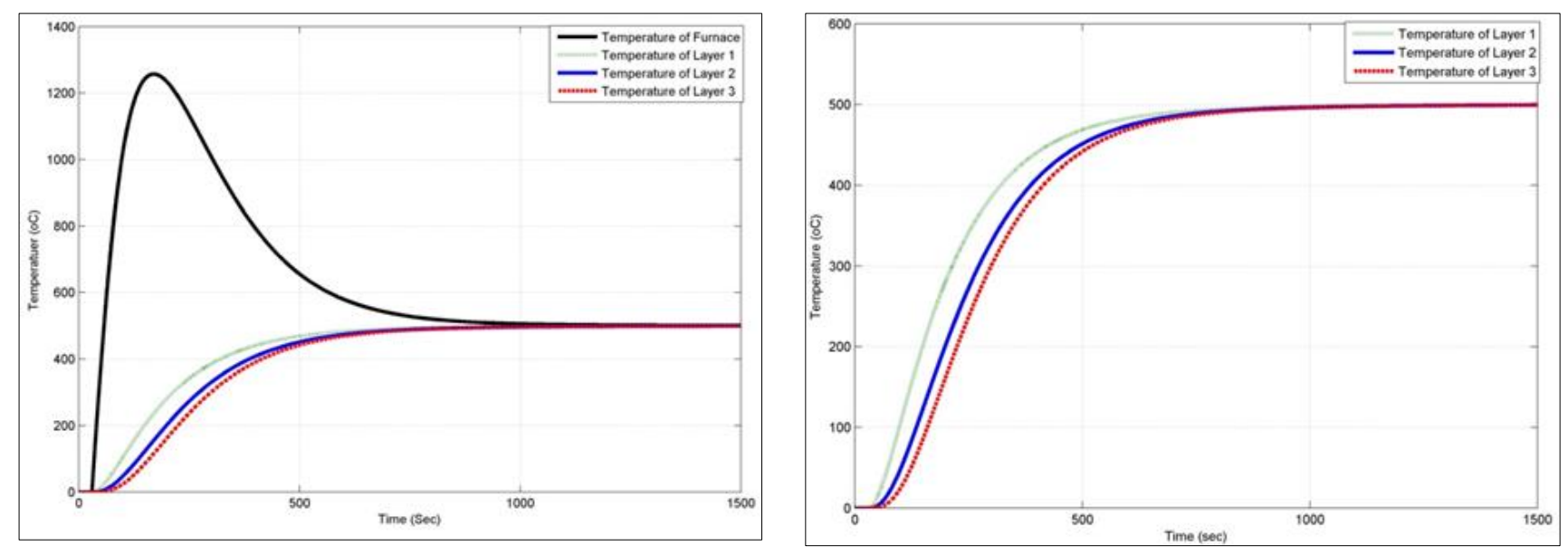

Figure 8 Simulation results of 3-layer slab temperature control system when using filter

\section{Conclusion}

The article introduced a method of modeling slab by transfer function method. Based on the transfer function model of the slab, the authors have designed the PID controller according to the characteristic polynomial method. The simulation results show that the PID controller is capable of controlling the temperature of the slab to the desired temperature without over-adjusting. We also offer a solution to save heating energy for the furnace by adding a filter behind the set signal. In the next studies, we will conduct experiments on real systems to verify the correctness of the research in practice.

\section{Compliance with ethical standards}

\section{Acknowledgments}

The authors gratefully acknowledge the Thai Nguyen University of Technology for supporting this work.

\section{Disclosure of conflict of interest}

The authors declare that they have no conflicts of interest.

\section{References}

[1] Bui Hai, Tran The Son. Heat engineering. Ha Noi: Science and Technology Publishing House; 2004.

[2] Dang Quoc Phu, Tran The Son, Tran Van Phu. Heat Transfer. 3rd. Ha Noi: Viet Nam Education Publishing House Limited Company; 2007.

[3] Nguyen Huu Cong. Optimal control for objects with slow distribution parameters [Ph.D. dissertation]. Ha Noi, Viet Nam: Hanoi University of Science and Technology; 2003.

[4] Minh Ngo Duc. Designing temperature observations and temperature controller of the plate slab [Engineering master thesis]. Thai Nguyen, Viet Nam: Thai Nguyen University of Technology; 2009.

[5] Kien Vu Ngoc, Cong Huu Nguyen, Duy Nguyen Tien. Designing the Controller Based On the Approach of Hedge Algebras and Application for Temperaturecontrol Problem of Slab. American Journal of Engineering Research (AJER). 2018; 7(6): 182-189.

[6] Kien Vu Ngoc, Cong Huu Nguyen. A Method for Building Mathematical Models of the Slab. International Journal of Innovative Science and Research Technology. 2018; 3(11): 439-443. 